\title{
A photosynthesis continuous monitoring system for CAM plants
}

\author{
Yongsan Cheng, Dongxian $\mathrm{He}^{*}$ \\ (Key Laboratory of Agricultural Engineering in Structure and Environment in Ministry of Agriculture and Rural Affairs, \\ China Agricultural University, Beijing 100083, China)
}

\begin{abstract}
Diurnal $\mathrm{CO}_{2}$ exchanges in crassulacean acid metabolism (CAM) plants are significantly different from those in $\mathrm{C} 3$ and $\mathrm{C} 4$ plants. The instantaneous short-time $\mathrm{CO}_{2}$ exchange of a single leaf measured by commercial portable photosynthesis measuring systems with a small leaf chamber cannot reflect the plant photosynthetic capacity for CAM plants because of the $\mathrm{CO}_{2}$ fixation property. Therefore, a photosynthesis continuous monitoring system with two canopy cuvettes was developed for measuring diurnal net $\mathrm{CO}_{2}$ exchange rates for CAM plants. To evaluate stability and applicability of the photosynthesis continuous monitoring system, continuous measurement of net $\mathrm{CO}_{2}$ exchange rates of plants with different photosynthetic pathways were conducted. An obligate CAM plant (Kalanchoe daigremontiana), four facultative CAM plants (Dendrobium officinale, D. chrysotoxum, D. nobile, and D. primulinum), a C3 plant (Strawberry, Fragaria ananassa), and a C4 plant (Corn, Zea mays) were selected as model plants. $K$. daigremontiana had a significant $\mathrm{CO}_{2}$ absorption during the dark period and its net $\mathrm{CO}_{2}$ exchange rates fluctuated around $0 \mu \mathrm{mol} /\left(\mathrm{m}^{2} \cdot \mathrm{s}\right)$ during the photoperiod in a growth chamber. Net $\mathrm{CO}_{2}$ exchange rates of $F$. ananassa and Z. mays in a greenhouse gradually increased after sunrise, reaching a maximum at about 12:00, and then gradually decreased to negative values during the night time. It is interesting to observe that $D$. officinale in the greenhouse and growth chamber absorbed $\mathrm{CO}_{2}$ during both day and night times. The photosynthetic pathways of D. chrysotoxum, D. nobile, and $D$. primulinum were also well distinguished by this photosynthesis continuous monitoring system. The results showed that the photosynthesis continuous monitoring system is capable for quantitative evaluation of diurnal net $\mathrm{CO}_{2}$ exchange characteristics not only in the CAM plants but also in small size C3 and C4 plants with low net photosynthetic rates for long-time and high-accuracy measurements.
\end{abstract}

Keywords: diurnal net $\mathrm{CO}_{2}$ exchanges, infrared $\mathrm{CO}_{2}$ analyzer, mass airflow meter, net photosynthetic rate, photosynthetic pathway

DOI: $10.25165 /$ j.ijabe.20191203.4885

Citation: Cheng Y S, He D X. A photosynthesis continuous monitoring system for CAM plants. Int J Agric \& Biol Eng, 2019; 12(3): 141-146.

\section{Introduction}

Crassulacean acid metabolism (CAM) is one of the three photosynthetic pathways of vascular plants and special photosynthetic metabolic adaption to environmental stress. This is modified on the basis of $\mathrm{C} 3$ pathway, which increases the $\mathrm{CO}_{2}$ concentration around Rubisco, thereby inhibiting photorespiration. CAM pathway involves a temporal separation of $\mathrm{CO}_{2}$ fixation from atmosphere predominantly at night time by opening stomata and subsequently assimilating this $\mathrm{CO}_{2}$ to carbohydrate during day time. During the night time, ambient $\mathrm{CO}_{2}$ is fixed into malic acid via phosphoenolpyruvate carboxylase (PEPC) and oxaloacetic acid, which accumulates in the mesophyll cells containing chloroplasts. In the following photoperiod, the $\mathrm{CO}_{2}$ released is subsequently fixed by Rubisco in the Calvin cycle. Decarboxylation of malic acid produces a high intercellular $\mathrm{CO}_{2}$ concentration, which causes stomatal closure during the day time ${ }^{[1]}$. The photosynthetic pathways of $\mathrm{C} 3$ and $\mathrm{C} 4$ plants are known to have different photosynthetic properties from CAM plants ${ }^{[2-4]}$. C3 and $\mathrm{C} 4$ plants show $\mathrm{CO}_{2}$ fixation during the day time and $\mathrm{CO}_{2}$ release at night

Received date: 2019-01-07 Accepted date: 2019-04-23

Biographies: Yongsan Cheng, $\mathrm{PhD}$ candidate, research interests: plant environmental physiology, Email: 348522460@qq.com.

*Corresponding author: Dongxian He, PhD, Professor, research interests: plant environmental physiology and bio-environment engineering. Key Lab. Agricultural Engineering in Structure and Environment in Ministry of Agriculture and Rural Affairs, China Agricultural University, Beijing 100083, China. Tel/Fax: +86-10-62737550, Email: hedx@cau.edu.cn. time. Net $\mathrm{CO}_{2}$ exchange rates of CAM plants in day time are minus or low because of closed stomata or non-uniform stomata closure. The diurnal net $\mathrm{CO}_{2}$ exchange pattern for CAM plants is more complicated than those of $\mathrm{C} 3$ and $\mathrm{C} 4$ plants. The photosynthetic characteristics of CAM plants are very difficult to be accurately reflected by the use of small chambers and discontinuous measurements. Continuously measuring the diurnal net $\mathrm{CO}_{2}$ exchange rates of the whole plant can distinguish the different photosynthetic pathway ${ }^{[5]}$.

Extent of CAM pathway relative to regular C3 pathway is considerably variable. Depending on plant species, ontogeny, and environment, the contribution of nocturnal $\mathrm{CO}_{2}$ fixed to daily carbon gain can range from nearly $0 \%$ to $100 \%{ }^{[6]}$. In its weakest form, the average $\mathrm{CO}_{2}$ fixation rate may be less than 0.1 $\mu \mathrm{mol} /\left(\mathrm{m}^{2} \cdot \mathrm{s}\right)$, which is challenging to distinguish using conventional commercial portable photosynthesis measuring system ${ }^{[7]}$. With more biomass or larger leaf area in the leaf chamber, accuracy of photosynthesis measurement at low net photosynthetic rates can be improved $^{[8-14]}$.

Commercial portable photosynthesis measuring systems are developed for measuring short-time net $\mathrm{CO}_{2}$ exchange rate based on photosynthetic properties of $\mathrm{C} 3$ and $\mathrm{C} 4$ plants ${ }^{[15-17]}$. Thus, the photosynthetic capacity of CAM plants is hard to be accurately assessed by net $\mathrm{CO}_{2}$ exchange rate of a leaf using this kind of instruments. Therefore, a continuous monitoring system with a bigger leaf chamber for photosynthesis determination was developed in this study to continuously measure diurnal net $\mathrm{CO}_{2}$ exchange rates for CAM plants. 
Dendrobium is the second largest genera of Orchidaceae plants with 1500 to 1600 native species, mainly distributed in tropical Asia and Pacific islands. There are about 76 species in China and one-sixth of them are used medicinally with high economic value $^{[18]}$. Several Dendrobium species as important ornamental plants and medicinal plants were used for photosynthesis research and industrial application ${ }^{[19-23]}$. Many Dendrobium species have evolved into CAM photosynthetic pathways in adapting to harsh epiphytic environment ${ }^{[24]}$. Su and Zhang measured the diurnal net $\mathrm{CO}_{2}$ exchange rates of $D$. officinale under various weather conditions and found that it had a CAM photosynthetic pattern on sunny days, a $\mathrm{C} 3$ photosynthetic pattern on rainy days, and an intermediate photosynthetic pattern between CAM and C3 on cloudy days ${ }^{[21]}$. D. officinale was identified as an obvious facultative CAM plant by continuously measuring the diurnal net $\mathrm{CO}_{2}$ exchange rate during water stress and different light/dark cycles $^{[25]}$. D. chrysotoxum and D. nobile showed C3 photosynthetic pathway under well-watered conditions and switched from C3 pathway to CAM photosynthesis under drought stress; thus, these two species were facultative CAM plants. Yang et al. reported that diurnal net $\mathrm{CO}_{2}$ exchange rate in $D$. primulinum had four distinct phases in the 24-h CAM photosynthetic cycle ${ }^{[28]}$. However, most of the above results were based on portable photosynthesis measuring instruments. Therefore it requires further confirmation with a novel photosynthesis continuous monitoring system.

\section{Materials and methods}

\subsection{System description}

A photosynthesis continuous monitoring system consists of a host computer box, two cuboid acrylic canopy cuvettes, four gas circuit pipes, two communication lines connected to two photosynthetic photon flux density (PPFD) sensors and two communication lines connected to two temperature control modules (Figure 1). It was developed to measure diurnal net $\mathrm{CO}_{2}$ exchange rates for CAM plants. The plant shoots are enclosed in the cuvettes while the roots and substrate are excluded. The host computer box consists of an infrared $\mathrm{CO}_{2}$ analyzer (GXH-3052, Beijing Beifen-Ruili Analytical Instrument Co., Beijing, China), two air pumps (FML201.5, Chengdu Qihai E\&M Manufacturing Co., Chengdu, China), three mass airflow meters (AWM5102, Honeywell International, Morristown, NJ, USA), one temperature control module for cuvette temperature control, and an embedded computer. Two of the mass airflow meters are connected to the two cuvettes and the other one is connected to the $\mathrm{CO}_{2}$ analyzer. Each cuvette with $250 \mathrm{~mm} \times 150 \mathrm{~mm} \times 60 \mathrm{~mm}$ is equipped with a small fan for mixing air inside. The airflow is controlled by an air pump forcing the airflow from inlet to outlet of the cuvette. A quantum sensor (LI-190SA, LI-COR Inc., Lincoln, NE, USA) is fitted at the upside of each cuvette for measuring the PPFD. The temperature inside the cuvette is controlled by the temperature control module based on either atmospheric temperature tracking mode or fixed temperature control mode.

The net $\mathrm{CO}_{2}$ exchange rate, $\mu \mathrm{mol} /\left(\mathrm{m}^{2} \cdot \mathrm{s}\right)$, for plants inside the cuvette is calculated as follows:

\section{Net $\mathrm{CO}_{2}$ exchange rate $=k \times\left(C_{\text {inlet }}-C_{\text {outlet }}\right) \times F / L A$}

where, $k$ is the conversion coefficient, $\mathrm{mol} / \mathrm{L} ; C_{\text {inlet }}$ and $C_{\text {outlet }}$ are $\mathrm{CO}_{2}$ concentrations at inlet and outlet of the cuvette, respectively, $\mu \mathrm{mol} / \mathrm{mol} ; F$ is airflow rate, $1.0 \mathrm{~L} / \mathrm{min}$; and $L A$ is leaf area, $\mathrm{m}^{2}$. The $L A$ was determined according to Yang et al. ${ }^{[26]}$

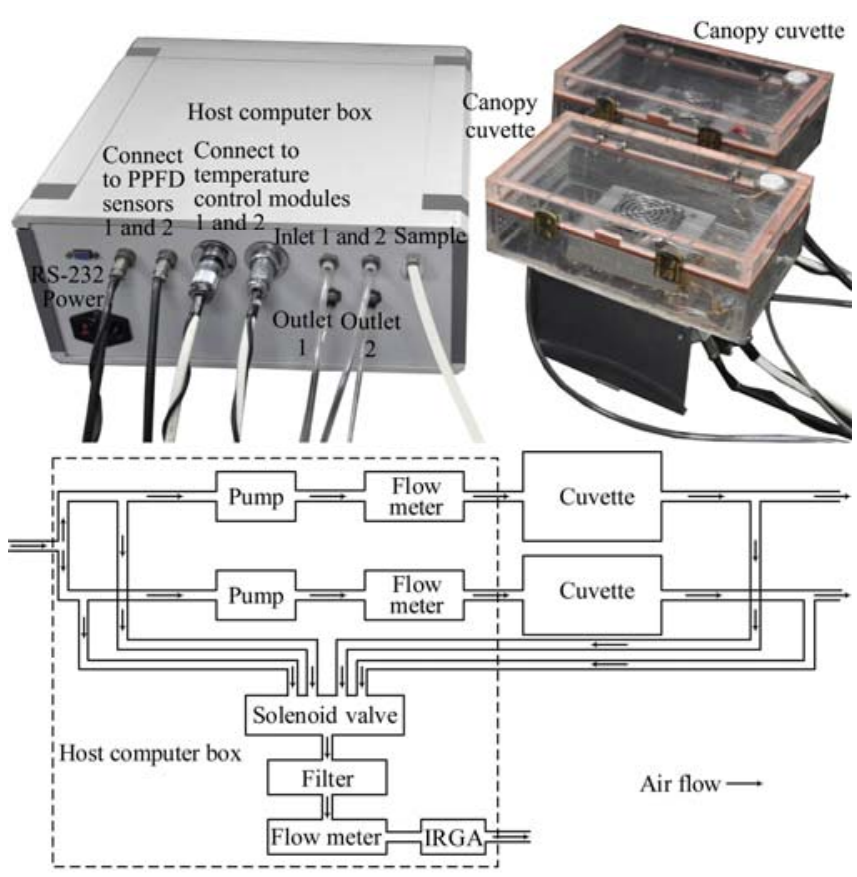

Figure 1 System composition and schematic diagram of gas circuit in the photosynthesis continuous monitoring system

2.2 Plant cultivation and net $\mathrm{CO}_{2}$ exchange rate measurements of plants with different photosynthetic pathways

To evaluate the stability and applicability of the photosynthesis continuous monitoring system, net $\mathrm{CO}_{2}$ exchange rates of four species with different photosynthetic pathways were continuously measured in two different greenhouses and a growth chamber for two days (Figure 2). An obligate CAM plant (Kalanchoe daigremontiana), a facultative CAM plant (D. officinale), a C3 plant (Strawberry, Fragaria ananassa), and a C4 plant (Corn, Zea mays) were selected for evaluating the system stability. $F$. ananassa, Z. mays, and $K$. daigremontiana plants were cultivated in a greenhouse located at College of Water Resources and Civil Engineering, China Agricultural University, Beijing, China. The range of maximum PPFD of each day during the measurement was $600-620 \mu \mathrm{mol} /\left(\mathrm{m}^{2} \cdot \mathrm{s}\right)$. The range of temperature, relative humidity, and $\mathrm{CO}_{2}$ concentration in the greenhouse were $14^{\circ} \mathrm{C}-29^{\circ} \mathrm{C}, 24 \%-53 \%$, and $310-650 \mu \mathrm{mol} / \mathrm{mol}$, respectively. The plants were grown in $0.4-\mathrm{L}$ round plastic pots (two plants per pot) filled with a substrate mixture of composted small pine bark (3-8 $\mathrm{mm})$, medium pine bark (5-10 mm), pine bark powder, perlite, and composted sawdust in a volume ratio of $1: 1: 1: 1: 0.5$. The $D$. officinale were cultured under artificial lighting with $12 \mathrm{~h} / \mathrm{d}$ photoperiod and $160 \mu \mathrm{mol} /\left(\mathrm{m}^{2} \cdot \mathrm{s}\right)$ PPFD provided by fluorescent lamps in a walk-in growth chamber at the same building. Inside the growth chamber, the average air temperature was controlled at $25.0^{\circ} \mathrm{C} \pm 1.0^{\circ} \mathrm{C}$, relative humidity was controlled at $65 \% \pm 5 \%$, and $\mathrm{CO}_{2}$ concentration was controlled at $500 \pm 50 \mu \mathrm{mol} / \mathrm{mol}$. The plants in both greenhouse and growth chamber were watered with nutrient solution once every $2 \mathrm{~d}$ or $3 \mathrm{~d}$ as the plant needed.

When $F$. ananassa, Z. mays, and $K$. daigremontiana plants had 8,4 and 6 leaves, respectively, their net $\mathrm{CO}_{2}$ exchange rates were measured using the photosynthesis continuous monitoring system in the greenhouse. When the D. officinale plants had 12 leaves, their net $\mathrm{CO}_{2}$ exchange rate was measured using a fluorescence leaf chamber (6400-40, LI-COR Inc., Lincoln, NE, USA) and a conifer leaf chamber (6400-05, LI-COR Inc., Lincoln, NE, USA) controlled by a portable photosynthesis measuring system (LI-6400XT; LI-COR Inc., Lincoln, NE, USA) in the growth 
chamber. The measurement of net $\mathrm{CO}_{2}$ exchange rate for $D$. officinale was also conducted by the photosynthesis continuous monitoring system in the growth chamber and in an unheated commercial greenhouse located in Jinhua City, Zhejiang Province, China. The annual average air temperature in Jinhua greenhouse was $17.5^{\circ} \mathrm{C}$, the lowest and highest air temperatures were $-2.8^{\circ} \mathrm{C}$ and $38.9^{\circ} \mathrm{C}$, respectively. The range of maximum PPFD of each day during measurement was $100-360 \mu \mathrm{mol} /\left(\mathrm{m}^{2} \cdot \mathrm{s}\right)$ (Figure 2). The range of temperature, relative humidity, and $\mathrm{CO}_{2}$ concentration in the greenhouse during measurement were $7^{\circ} \mathrm{C}-22^{\circ} \mathrm{C}, 30 \%-66 \%$, and $316-476 \mu \mathrm{mol} / \mathrm{mol}$, respectively.

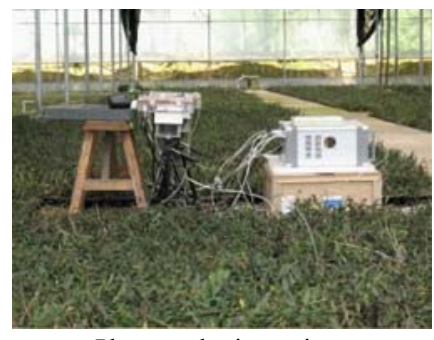

a. Photosynthesis continuous monitoring system in the greenhouse

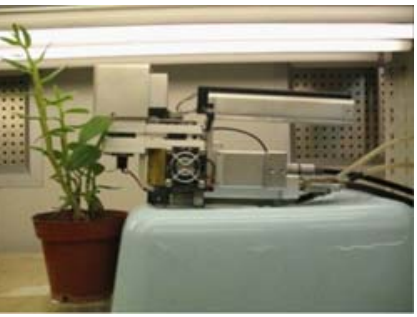

c. Portable photosynthesis measuring system with a fluorescence leaf chamber system with a conifer leaf chamber in in the growth chamber

the growth chamber

Figure 2 Photosynthesis measurements of Dendrobium officinale

2.3 Continuous measurements of net $\mathrm{CO}_{2}$ exchange rates for photosynthetic pathway determination of Dendrobium plants

$D$. chrysotoxum, D. nobile, and D. primulinum plants from Puer City, Yunnan Province, China were cultured in the same growth chamber for three months. The cultured environment conditions and irrigation management were the same as those mentioned above for $D$. officinale. When they have 10 leaves, the diurnal net $\mathrm{CO}_{2}$ exchange rates of these three Dendrobium species were measured by the photosynthesis continuous monitoring system in the growth chamber for 3 days. The diurnal net $\mathrm{CO}_{2}$ exchange rates of $K$. daigremontiana with 6 leaves as an obligate CAM plant were also simultaneously measured by the same system as a reference. The photosynthetic pathways of Dendrobium plants were determined by dark net $\mathrm{CO}_{2}$ exchange percentage which was calculated by the formula ${ }^{[25]}$ :

Dark net $\mathrm{CO}_{2}$ exchange percentage $=$

$$
\frac{\text { Dark net } \mathrm{CO}_{2} \text { exchange amount }}{\text { Daily net } \mathrm{CO}_{2} \text { exchange amount }} \times 100 \%
$$

where, dark net $\mathrm{CO}_{2}$ exchange amount was defined as the integrated net $\mathrm{CO}_{2}$ exchange amount of the dark period, and daily net $\mathrm{CO}_{2}$ exchange amount was defined as the integrated $\mathrm{CO}_{2}$ exchange amount of $24 \mathrm{~h}$.

\section{Results and discussion}

3.1 Performance tests of the photosynthesis continuous monitoring system

Net $\mathrm{CO}_{2}$ exchange rates of the empty cuvettes were measured before and after each photosynthesis measurement. The $\mathrm{CO}_{2}$ concentrations in the inlet and the outlet were close to each other (Figure 3a). The noise level which is the difference in $\mathrm{CO}_{2}$ concentrations between inlet and outlet of the empty cuvette, was about $\pm 3.3 \mu \mathrm{mol} / \mathrm{mol}$ (Figure $3 \mathrm{~b}$ ). Therefore, the photosynthetic capacity of plants could be truly reflected by the photosynthesis continuous monitoring system only if the $\mathrm{CO}_{2}$ concentration difference between the inlet and outlet of the cuvette was greater than $3.3 \mu \mathrm{mol} / \mathrm{mol}$. The cuvette temperature was controlled at $25.2^{\circ} \mathrm{C} \pm 0.3^{\circ} \mathrm{C}$ by using the fixed temperature control mode (Figure 4a) with a target of $25.0^{\circ} \mathrm{C}$ or well controlled by temperature tracing mode (Figure $4 \mathrm{~b}$ ). The fixed temperature control mode was of particular importance for studying the endogenous rhythms of CAM plants under constant environmental conditions ${ }^{[27]}$. The temperature tracing mode was particularly important for studying the response and adaptation of CAM plants to changes in the surrounding environment ${ }^{[28]}$. Therefore, the photosynthesis continuous monitoring system could be used to measure diurnal $\mathrm{CO}_{2}$ exchange rates for CAM plants owning to the high detection accuracy and independence of its systematic error.

3.2 Continuous measurements of net $\mathrm{CO}_{2}$ exchange rate of plants with different photosynthetic pathways

The $K$. daigremontiana plants had a large amount of net $\mathrm{CO}_{2}$ absorption during the dark period with a peak value at about 04:00 and fluctuated around $0 \mu \mathrm{mol} /\left(\mathrm{m}^{2} \cdot \mathrm{s}\right)$ during the photoperiod (Figure 5). Net $\mathrm{CO}_{2}$ exchange rates of $F$. ananassa and Z. mays plants gradually increased after sunrise and reached a maximum at about 12:00 which were $6.2 \mu \mathrm{mol} /\left(\mathrm{m}^{2} \cdot \mathrm{s}\right)$ and $11.2 \mu \mathrm{mol} /\left(\mathrm{m}^{2} \cdot \mathrm{s}\right)$, respectively, and then gradually decreased to a negative value in the night time. These results showed that the photosynthesis continuous monitoring system was suitable not only for quantitative evaluation of the diurnal net $\mathrm{CO}_{2}$ exchange characteristics for CAM plants, but also for $\mathrm{C} 3$ and $\mathrm{C} 4$ plants for a long-time measurement because of the diurnal automatic monitoring and higher measurement accuracy.

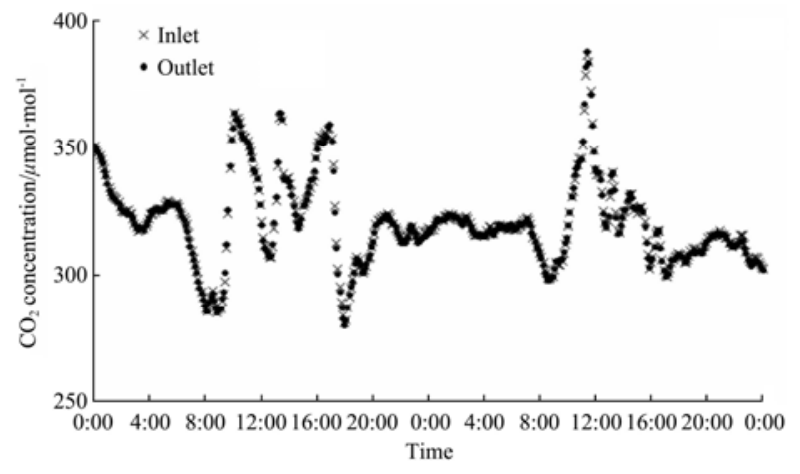

a. $\mathrm{CO}_{2}$ concentration in the inlet and outlet of cuvette

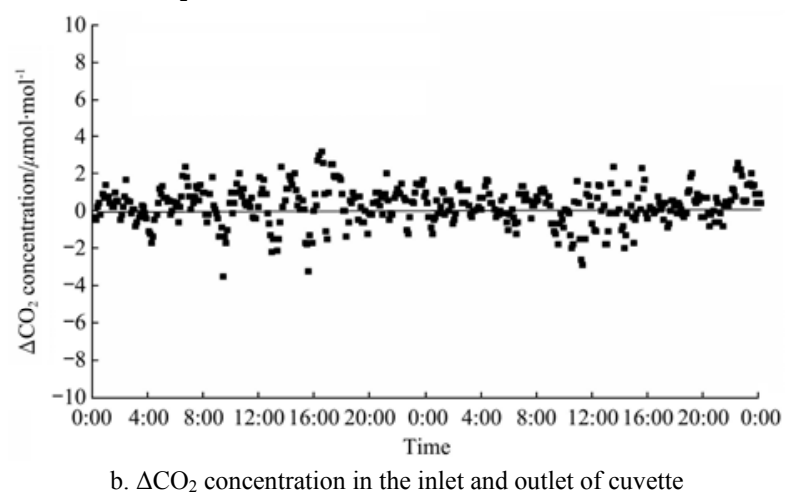

Figure 3 Time course of $\mathrm{CO}_{2}$ concentration and $\Delta \mathrm{CO}_{2}$ concentration in the inlet and outlet of cuvette (the photosynthesis continuous monitoring system was supplied by compressed air for $2 \mathrm{~d}$ ) 

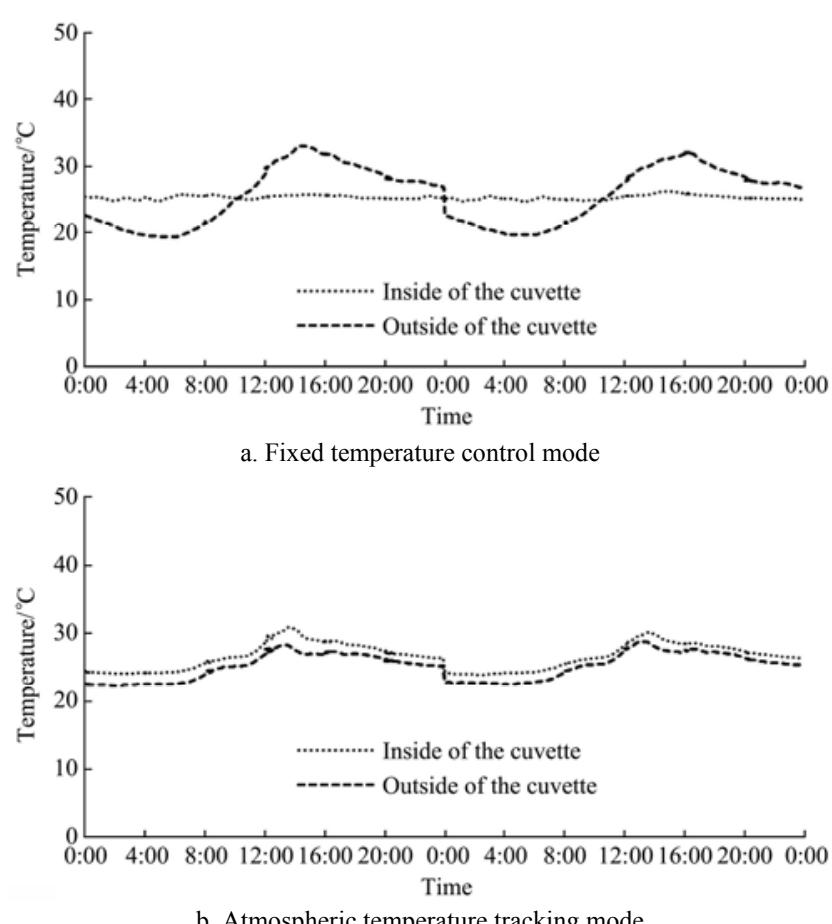

Figure 4 Time course of temperature in outside and inside the cuvette of the photosynthesis continuous monitoring system by using fixed temperature control mode with a target at $25.0^{\circ} \mathrm{C}$ and atmospheric temperature tracking mode

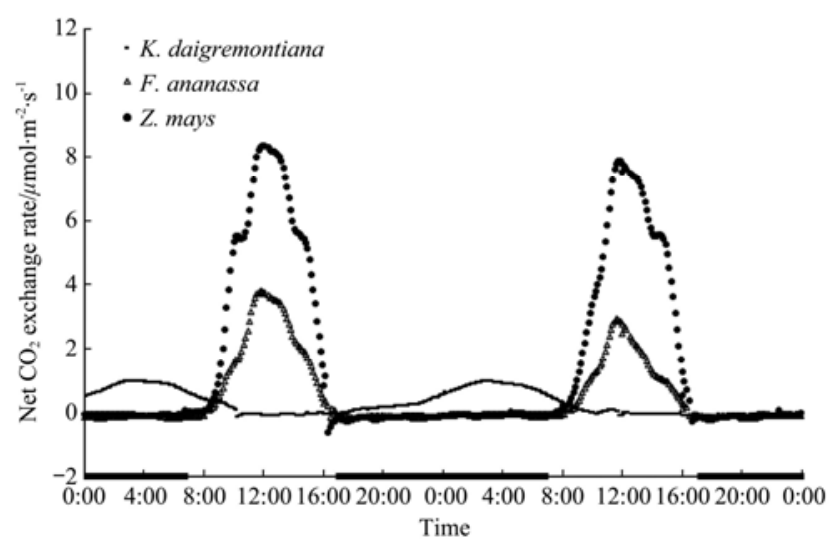

Note: The atmospheric temperature tracking mode was used. Dark bar in the $x$-axis indicates the dark period in the greenhouse.

Figure 5 Time course of net $\mathrm{CO}_{2}$ exchange rates of $K$. daigremontiana as an obligate CAM plant, $F$. ananassa as a $\mathrm{C} 3$ plant, and $Z$. mays as a $\mathrm{C} 4$ plant measured continuously by the photosynthesis continuous monitoring system in Beijing greenhouse for $2 \mathrm{~d}$

3.3 Continuous net $\mathrm{CO}_{2}$ exchange rate measurements of $\mathrm{D}$. officinale as a facultative CAM plant

When measured every $3 \mathrm{~min}$ by fluorescence leaf chamber of a portable photosynthesis measuring system (LI-6400XT), net $\mathrm{CO}_{2}$ exchange rates of a single leaf between $-2.0 \mu \mathrm{mol} /\left(\mathrm{m}^{2} \cdot \mathrm{s}\right)$ to $4.0 \mu \mathrm{mol} /\left(\mathrm{m}^{2} \cdot \mathrm{s}\right)$ with large fluctuations were observed for $D$. officinale as a facultative CAM plant in the growth chamber (Figure 6). It was not possible to judge whether the net $\mathrm{CO}_{2}$ exchange rates were positive or negative due to the large variations. By using a conifer leaf chamber controlled by the same portable photosynthesis measuring system with multiple leaves enclosed, the net $\mathrm{CO}_{2}$ exchange rates had smaller fluctuations with low value less than $2.0 \mu \mathrm{mol} /\left(\mathrm{m}^{2} \cdot \mathrm{s}\right)$. However, with the photosynthesis continuous monitoring system in the growth chamber, the net $\mathrm{CO}_{2}$ exchange rates of the whole plant had a peak value at $2.5 \mu \mathrm{mol} /\left(\mathrm{m}^{2} \cdot \mathrm{s}\right)$ and decreased to stable value at $1.5 \mu \mathrm{mol} /\left(\mathrm{m}^{2} \cdot \mathrm{s}\right)$ (Figure 7a). The diurnal net $\mathrm{CO}_{2}$ exchange rates with fluctuating PPFD could also be well measured in the greenhouse. The net $\mathrm{CO}_{2}$ exchange rate of $D$. officinale firstly had a sharp increase with the PPFD in the morning, then decreased to almost $0 \mu \mathrm{mol} /\left(\mathrm{m}^{2} \cdot \mathrm{s}\right)$ after 12:00, and had a small peak in the afternoon (Figure $7 \mathrm{~b}$ ). The net $\mathrm{CO}_{2}$ exchange rates of $D$. officinale in the growth chamber and greenhouse were positive by this photosynthesis continuous monitoring system (Figure 7). These results indicated that increasing leaf area or biomass within the cuvette could improve the measurement accuracy for species with low net $\mathrm{CO}_{2}$ exchange

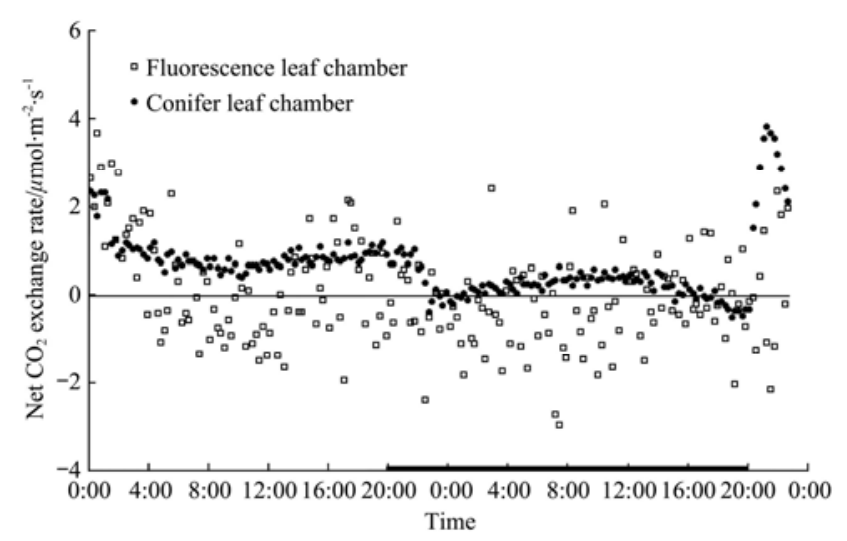

Note: Dark bar in the $x$-axis indicates the dark period in the growth chamber.

Figure 6 Time course of net $\mathrm{CO}_{2}$ exchange rate of $D$. officinale measured by the portable photosynthesis measuring system

(LI-6400XT) with a conifer chamber for multiple leaves and a fluorescence chamber for a single leaf
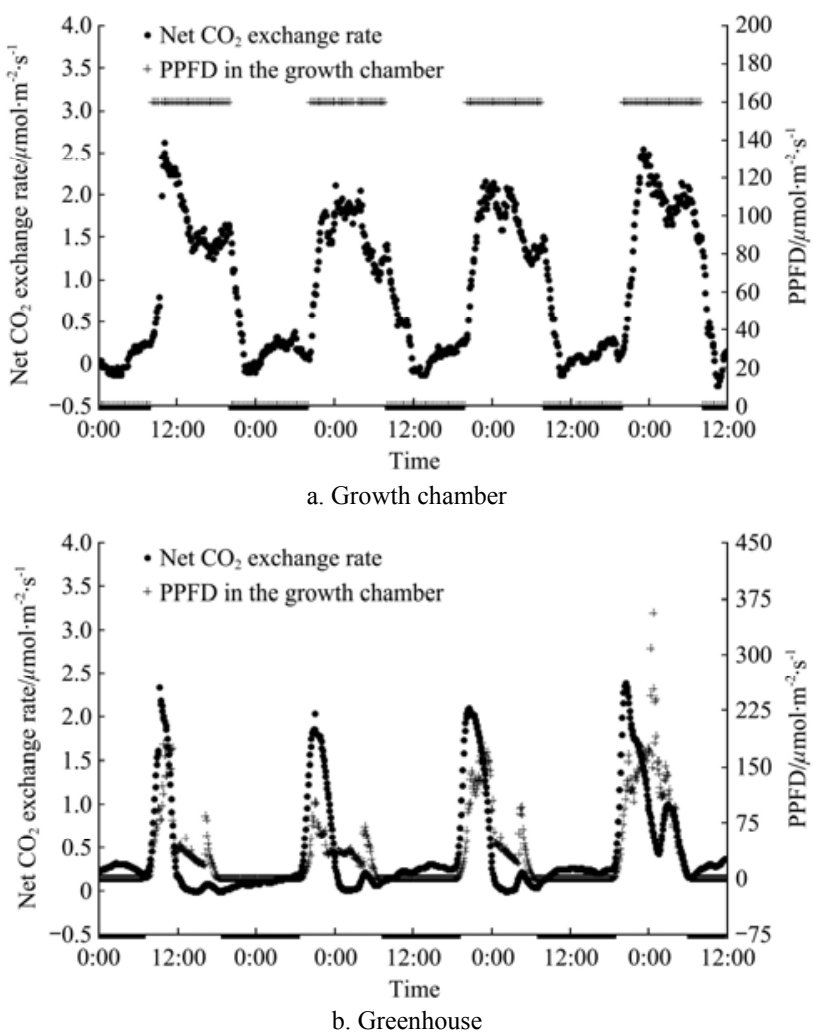

Note: The atmospheric temperature tracking mode was used. Dark bar in the $x$-axis indicates the dark period in the growth chamber and greenhouse respectively.

Figure 7 Time course of net $\mathrm{CO}_{2}$ exchange rates of $D$. officinale measured continuously by the photosynthesis continuous monitoring system in the growth chamber and greenhouse for $4 \mathrm{~d}$ 
rates such as $D$. officinale. From the non-continuously measured net $\mathrm{CO}_{2}$ exchange rates of $D$. officinale by the portable photosynthesis measuring system, the photosynthetic pathway of CAM plants could not be accurately determined because of the small leaf chamber of the instrument and the stomata opening property of the CAM plants ${ }^{[18]}$.

Based on continuous measurement of diurnal net $\mathrm{CO}_{2}$ exchange rates, the photosynthetic characteristics of CAM plants in $\mathrm{CO}_{2}$ absorption during the night time could be obviously reflected (Figure 7). The photosynthesis continuous monitoring system not only solved the problem of low net $\mathrm{CO}_{2}$ exchange rates of $D$. officinale plants with a relatively sharp instrumental noise, but also reduced sampling error. Moreover, the commercial portable photosynthetic measuring system generally measures a small portion of a leaf, which cannot represent the photosynthetic characteristics of the whole plant.

3.4 Continuous net $\mathrm{CO}_{2}$ exchange rate measurements for photosynthetic pathways determination of other Dendrobium plants

Diurnal net $\mathrm{CO}_{2}$ exchange rates of $D$. chrysotoxum were similar to those of $\mathrm{C} 3$ plants, which featured negative values in the dark period. The net $\mathrm{CO}_{2}$ exchange rate of $D$. nobile during the dark period was around $0 \mu \mathrm{mol} /\left(\mathrm{m}^{2} \cdot \mathrm{s}\right)$, and that in photoperiod was positive (Figure 8). Net $\mathrm{CO}_{2}$ exchange rate of $D$. primulinum showed obvious four-phase changes in photosynthetic characteristics in typical CAM plants, namely, the net $\mathrm{CO}_{2}$ uptake in the dark period (phase I), the rise at the beginning of the photoperiod (phase II), almost zero in the middle of the photoperiod (phase III), and the rise in the late photoperiod (phase IV). The dark net $\mathrm{CO}_{2}$ exchange percentages were more $50 \%$ for $D$. primulinum, negative value for $D$. chrysotoxum, and close to $0 \%$ for $D$. nobile, respectively. The net $\mathrm{CO}_{2}$ exchange rates of $K$. daigremontiana as the obligate CAM plant were around $0 \mu \mathrm{mol} /\left(\mathrm{m}^{2} \cdot \mathrm{s}\right)$ most of the time in the photoperiod and had positive values in the dark period, while the phase IV was not obvious. The dark net $\mathrm{CO}_{2}$ exchange percentage of $K$. daigremontiana reached more than $90 \%$.

Based on the proportion of daily net $\mathrm{CO}_{2}$ fixation occupied by dark net $\mathrm{CO}_{2}$ fixation, different extent of CAM plants could be distinguished easily ${ }^{[2,30]}$. This indicated that the photosynthetic pathway of $D$. chrysotoxum should match $\mathrm{C} 3$ property in this environment and the $D$. nobile was mainly in $\mathrm{C} 3$ property with a weak CAM feature. However, D. chrysotosum could not be considered as a C3 plant, because many facultative CAM plants usually showed C3 pathway under well irrigated conditions, and only under drought stress could they show CAM pathway ${ }^{[31-33]}$. More accurately, D. nobile at this time was closer to the "Nearly-C3" or "CAM cycling" type ${ }^{[34]}$. The photosynthetic pathway of $D$. primulinum was mainly in CAM property with some C3 feature (Figure 8). These results were in consistence with findings of Ren's team by measuring the activity of phosphoenolpyruvate carboxylase (PEPC $)^{[35]}$. K. daigremontiana exhibited a full CAM pathway. Compared to the results of three Dendrobium plants obtained by portable photosynthetic systems ${ }^{[29]}$, this continuous photosynthetic system could more accurately evaluate the photosynthetic pathway of Dendrobium plants. Therefore, Dendrobium plants with different extents of CAM property could be well distinguished by this photosynthesis continuous monitoring system. The dark net $\mathrm{CO}_{2}$ exchange percentage can be used to evaluate quantitatively the CAM photosynthetic property and distinguish easily the obligate or facultative CAM plants.

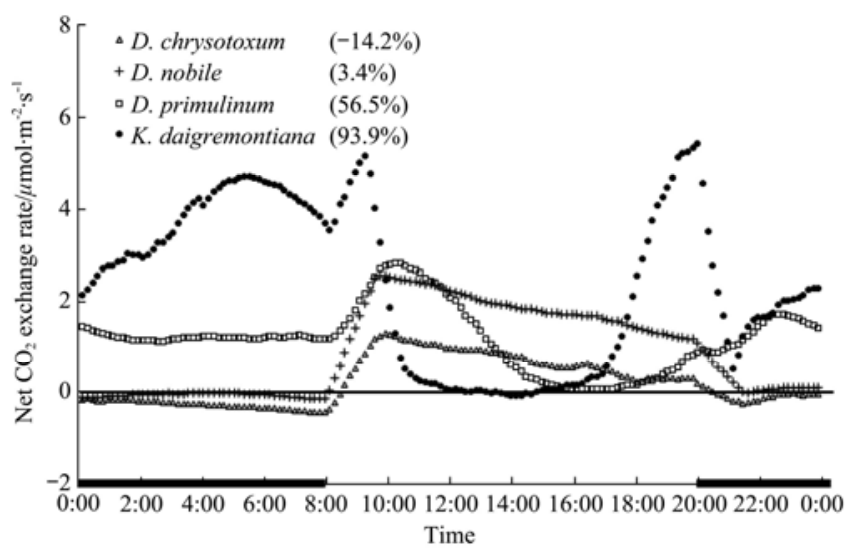

Note: The atmospheric temperature tracking mode was used. Dark bar in the $x$-axis indicates the dark period in the growth chamber. The numbers in the legend are the averages of dark net $\mathrm{CO}_{2}$ exchange percentage of 3 days for these four species.

Figure 8 Diurnal net $\mathrm{CO}_{2}$ exchange rates of $D$. chrysotoxum, $D$. nobile, D. primulinum, and $K$. daigremontiana measured by the photosynthesis continuous monitoring system in the growth chamber

\section{Conclusions}

The diurnal net $\mathrm{CO}_{2}$ exchange rates measurement is suitable not only for CAM plant, but also for small size C3 and C4 plants with low photosynthetic rates due to the diurnal automatic monitoring and higher accuracy by using the photosynthesis continuous monitoring system. The system is also feasible to evaluate quantitatively CAM photosynthetic property and to distinguish easily the obligate or facultative CAM plants by using the dark net $\mathrm{CO}_{2}$ exchange percentage.

\section{Acknowledgements}

This work received the support of National Key Research and Development Project (2017YFB0403901). Thanks went to Mr. Zheng G M, Prof. Gao R F, Prof. Niu G H, and Prof. He J for their technical work and professional suggestions.

\section{[References]}

[1] Osmond C B. Crassulacean acid metabolism: a curiosity in context Annual Review of Plant Physiology, 1978; 29: 379-414.

[2] Flore J A, Stone fruit. In: Schaffer B, Andersen P C (Ed.), Handbook of environmental physiology of fruit crops. Volume I. Temperate crops, Boca Raton: CRC Press, 1994; pp. 233-270.

[3] Borland A M, Griffiths H. A comparative study on the regulation of C3 and $\mathrm{C} 4$ carboxylation processes in the constitutive crassulacean acid metabolism (CAM) plant Kalanchoe daigremontiana and the C3-CAM intermediate Clusia minor. Planta, 1997; 201(3): 368-378.

[4] Winter K, Holtum J A M. Facultative crassulacean acid metabolism (CAM) in four small C3 and C4 leaf-succulents. Australian Journal of Botany, 2017; 65(2): 103-108.

[5] Males J, Griffiths H. Stomatal biology of CAM plants. Plant Physiology, 2017; 174(2): 550-560.

[6] Winter K, Holtum J A M. Facultative crassulacean acid metabolism (CAM) plants: powerful tools for unravelling the functional elements of CAM photosynthesis. Journal of Experimental Botany, 2014; 65(13): 3425-3441.

[7] Winter K, Holtum J A M, Smith J A C. Crassulacean acid metabolism: A continuous or discrete trait? New Phytologist, 2015; 208(1): 73-78.

[8] Marur C J, Faria R T. A chamber for measurement of net photosynthesis on a whole plant. Acta Scientiarum-Agronomy, 2007; 29(3): 415-419.

[9] Miller D P, Howell G S, Flore J A. A whole-plant, open, gas-exchange system for measuring net photosynthesis of potted woody plants. 
HortScience, 1996; 31(6): 944-946.

[10] Corelli-Grappadelli L, Magnanini E. A whole-tree system for gas-exchange studies. HortScience, 1993; 28(1): 41-45.

[11] Marur C J, Faria R T. Photosynthesis of individual leaves in a coffee plant. Acta Scientiarum-Agronomy, 2006; 28(3): 331-335.

[12] Chen C, Hsu H C. Statistical technique for the evaluation of the effect of light quality on growing characteristics of in vitro cultures. Biosystems Engineering, 2009; 103(5): 257-264.

[13] Hsu H C, Chen C. The effect of light spectrum on the growth characteristics of in vitro cultures of Phalaenopsis. Propagation of Ornamental Plants, 2010; 10(1): 3-8.

[14] Gehrig H, Faist K, Kluge M. Identification of phosphoenolpyruvate carboxylase isoforms in leaf, stem and roots of the obligate CAM plant Vanilla planifolia Salib. (Orchidaceae): a physiological and molecular approach. Plant Molecular Biology, 1999; 38(6): 1215-1223.

[15] Catsky J, Ticha I. A closed system for measurement of photosynthesis, photorespiration and transpiration rates. Biologia Plantarum, 1976; 17(6): 405-410.

[16] Borland A M. A model for the partitioning of photosynthetically fixed carbon during the C3-CAM transition in Sedum telephium. New Phytologist, 1996; 134(3): 433-444.

[17] Zhang D Y, Wang X H, Chen Y, Xu D Q. Determinant of photosynthetic capacity in rice leaves under ambient air conditions. Photosynthetica, 2005; 43(2): 273-276

[18] Yang Z J, Zhang X, Zhang M J, Zhu G F, Wang B Q. The research advance in Dendrobium study. Acta Horticulturae Sinica, 2006; 33(6): 1389-1396.

[19] Ng T B, Liu J, Wong J H, Ye X, Sze S C W, Yao T, Zhang K Y. Review of research on Dendrobium, a prized folk medicine. Applied Microbiology Biotechnology, 2012; 93, 1795-1803.

[20] Teixeira Da Silva J A, Dobranszki J, Cardoso J C, Chandler S F, Zeng. Methods for genetic transformation in Dendrobium. Plant Cell Reports, 2016; 35: 483-504.

[21] Su W, Zhang G. The photosynthesis pathway in leaves of Dendrobium officinale. Acta Phytoecologica Sinica, 2003; 27, 631-637. (in Chinese)

[22] Yan L, Wang X, Liu H, Tian Y, Lian J, Yang R, et al. The genome of Dendrobium officinale illuminates the biology of the important traditional Chinese orchid herb. Molecular Plant, 2015; 8: 922-934.

[23] Ren J W, Bai W L. Advancement on elucidating geographical segregation in photosynthetic carbon assimilation pathway within genus
Dendrobium. Current Biotechnology, 2015; 5(1): 35-40 (in Chinese)

[24] Gehrig H, Heute V, Kluge M. New partial sequences of phosphoenolpyruvate carboxylase as molecular phylogenetic markers. Molecular Phylogenetics and Evolution, 2001; 20(2): 262-274.

[25] Zhang Z J, He D X, Niu G H, Gao R F. Concomitant CAM and C3 photosynthetic pathways in Dendrobium officinale plants. Journal of the American Society for Horticultural Science, 2014; 139(3): 290-298.

[26] Yang J, Chen C, Han X, Li X, Liebig H P. Measurement of vegetable leaf area using digital image processing techniques. Transactions of the CSAE, 2002; 18(4): 155-158. (in Chinese)

[27] Rascher U, Blasius B, Beck F, Lüttge U. Temperature profiles for the expression of endogenous rhythmicity and arrhythmicity of $\mathrm{CO}_{2}$ exchange in the CAM plant Kalanchoe daigremontiana can be shifted by slow temperature changes. Planta, 1998; 207: 76-82.

[28] Winter K, Holtum J A. How closely do the $\delta 13 \mathrm{C}$ values of crassulacean acid metabolism plants reflect the proportion of $\mathrm{CO}_{2}$ fixed during day and night? Plant Physiology, 2002; 129(4): 1843-1851.

[29] Yang L, Wang Y, Hu Q, Ren J. Comparative study on photosynthesis between three Dendrobium and Kalanchoe daigremontia. Journal of Shanxi Agricultural University (Nature Science Edition), 2011; 31(4): 294-301. (in Chinese)

[30] Winter K, Holtum J A. How closely do the $\delta 13 \mathrm{C}$ values of crassulacean acid metabolism plants reflect the proportion of $\mathrm{CO}_{2}$ fixed during day and night? Plant Physiology, 2002; 129(4): 1843-1851.

[31] Winter K, Holtum J A M. Environment or development? Lifetime net $\mathrm{CO}_{2}$ exchange and control of the expression of crassulacean acid metabolism in Mesembryanthemum crystallinum. Plant Physiology, 2007; 143: 98-107.

[32] Winter K, Garcia M, Holtum J A M. On the nature of facultative and constitutive CAM: environmental and developmental control of CAM expression during early growth of Clusia, Kalanchoë and Opuntia. Journal of Experimental Botany, 2008; 59(7): 1829-1840.

[33] Herrera A. Crassulacean acid metabolism and fitness under water deficit stress: If not for carbon gain, what is facultative CAM good for? Annals of Botany, 2009; 103(4): 645-653.

[34] Cushman J C. Crassulacean acid metabolism. A plastic photosynthetic adaptation to arid environments. Plant Physiology, 2001; 127(4): 1439-1448.

[35] Ren J W, Wang Y, Peng Z H, Zhang L C. Comparative study on PEPC activity in three Dendrobium leaves. Journal of Yunnan Agricultural University, 2011; 26(6): 815-820. (in Chinese) 